\title{
Complete globozoospermia associated with DPY19L2 mutation treated with calcium ionophore ionomycin and ICSI results in live birth
}

\author{
Shuai Liu*, Xiao Qun Liu, Hai Yan Huang, Zhang Quan Gao and Xiang Gai Zhang \\ Key Laboratory of Family planning and Health Birth, National Health and Family Planning Commission, Hebei Research Institute for Family Planning, China
}

\begin{abstract}
The successful outcome of intracytoplasmic sperm injection (ICSI) with round-headed spermatozoa (globozoospermia) and ionomycin assisted activation oocytes is reported. A 30-year-old man with $100 \%$ globozoospermia underwent ICSI treatment. Real-time Polymerase Chain Reaction (PCR) detection indicates that the patient was DPY19L2 homozygous deletion. Nine metaphase II oocytes were injected with round-headed sperms. After ICSI, the oocytes were activated with ionomycin. Two out of 9 metaphase II oocytes were fertilized after ICSI and ionomycin activation. One embryo was transferred and a singleton pregnancy was obtained that ended in the delivery of a healthy child. Our case reports demonstrate that artificial oocyte activation using calcium ionophore ionomycin is beneficial in patients with globozoospermia associated with DPY19L2 mutation, and the method of oocyte activation does not affect the normal growth of preimplantation embryos. Further studies are needed to confirm the safety of oocyte activation in born babies.
\end{abstract}

\section{Introduction}

Globozoospermia is a rare type of monomorphic teratozoospermia characterized by the absence, or reduced activity of acrosin and of calicin resulted in fertilization impaired due to absence of oocyte activation, the incidence is lower than $0.1 \%$. The mode of inheritance for this condition has not yet been established. Dominant inheritance, homozygous autosomal gene defect, and a possible environmental effect have been suggested. So far, three genes have been described as responsible for this phenotype: spermatogenesis associated 16 (SPATA16), protein interacting with PRKCA 1 (PICK1) and DPY19L2 [1-3].

Fertilization and pregnancies of globozoospermia can be achieved with ICSI, the first livebirth was reported in 1994 [4]; however, the success rates are generally very [5-8]. Several studies suggest that the low rate of fertilization in globozoospermic patients is partially caused by a decrease in the level or a defect in the oocyte activation factor, the phospholipase $\mathrm{C} \zeta$ (PLC $\zeta$ ), assumed to be the main physiologic factor responsible for oocyte activation [9-11]. It was shown that ICSI combined with assisted oocyte activation overcomes this fertilization failure for globozoospermic patients [12]. Oocyte activation is characterized by two main molecular events including an increase in intracellular $\mathrm{Ca}^{2+}$ concentrations followed by meiotic promoting factor inactivation for M-G1 transition. There are numerous approaches to overcome the problem of fertilization failure after ICSI. Among others, application of calcium ionophore has proved particularly advantageous because of their ease of operation. The primary role of the calcium signal is to down regulate the activity of the cell cycle regulatory protein M-phase promoting factor (MPF) that leads to exit from the metaphase arrest [13]. Several methods have been used to induce oocytes activation, including electric current and various chemical agents.

We report a case that to our knowledge, is the first report of pregnancy and delivery in couples with globozoospermia associated with DPY19L2 mutation after ICSI using ionomycin for oocyte activation.

\section{Case report}

A 30 year old man and his 29 year old partner who had not been pregnant for 4 years. They had gone through one ICSI cycle without oocyte activation with no embryo to transfer. A semen sample revealed the following characteristics: volume $2.8 \mathrm{ml}$; sperm concentration $100 \times 10^{6} / \mathrm{ml}$; sperm vitality: progressive motility $35 \%$, non- progressive motility $5 \%$, immotility $60 \%$, sperm morphology: All of the sperm were round-headed (Figures 1). His karyotype revealed a normal $46 \mathrm{XY}$ and $\mathrm{Y}$ chromosome microdeletion assay had not displayed microdeletions in the AZFa, AZFb, or AZFc regions. His hormonal level was within normal range. Real-time PCR detection indicates that the patient was DPY19L2 homozygous deletion, and his parents are carriers of DPY19L2 deletion.

His partner's history was unremarkable. She had regular menstrual cycle, her body mass index was $24.6 \mathrm{~kg} / \mathrm{m}^{2}$, FSH $5.65 \mathrm{IU} / \mathrm{L}, \mathrm{LH} 1.63$ IU/L, E2 $18.21 \mathrm{ng} / \mathrm{L}, \mathrm{PRL} 11.99 \mu \mathrm{g} / \mathrm{L}, \mathrm{T} 0.19 \mu \mathrm{g} / \mathrm{L}, \mathrm{P} 0.52 \mu \mathrm{g} / \mathrm{L}$ and antral follicle count 6-7.

Correspondence to: Shuai Liu, Key Laboratory of Family Planning and Health Birth, National Health and Family Planning Commission, Hebei Research Institute for Family Planning, 480 Heping Road, Shijiazhuang, Hebei Province, 050071 China, Tel/Fax: +86 31187041556, E-mail: liushuai601@126.com

Key words: hlobozoospermia, ionomycin, oocyte activation, intracytoplasmic sperm injection, male factor infertility

Received: May 29, 2016; Accepted: June 27, 2016; Published: June 30, 2016 


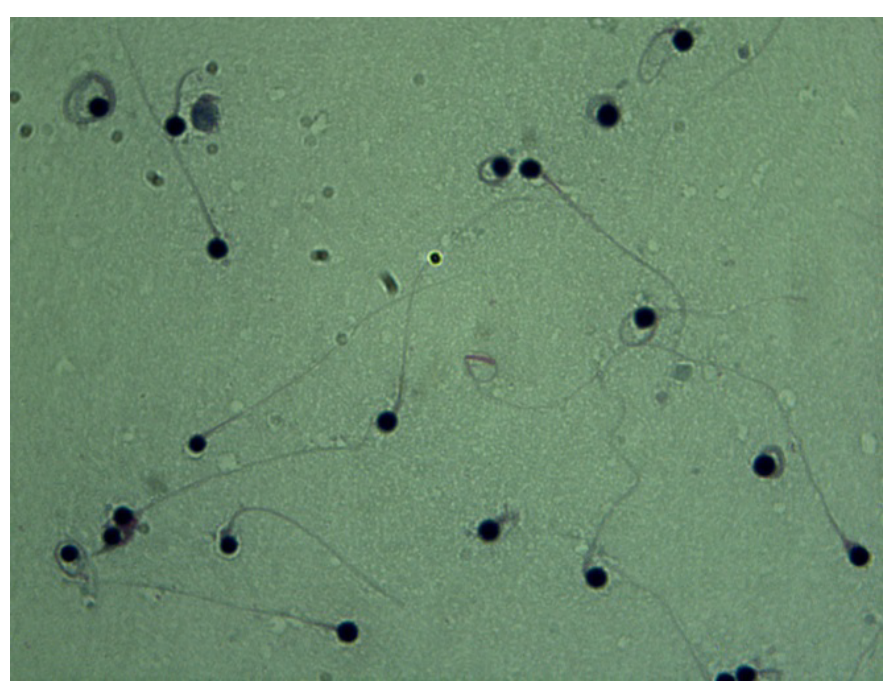

Figure 1. Morphology of round-headed sperm by Papanicolaou staining.

\section{Materials and methods}

\section{Sperm morphology assessment and analysis of gene expression}

Sperm morphology was assessed by Papanicolaou staining; all sperm analyses were performed at least three times in accordance with the recommendations of the World Health Organization (WHO). DPY19L2 expression was detected by Real-time PCR, the $2^{-\Delta \Delta \mathrm{Ct}}$ method was applied with the formula: relative amount of target gene mRNA= $2^{-\Delta \Delta \mathrm{Ct}}$, where CT is the threshold cycle for the gene amplification, $\Delta \mathrm{Ct}$ $=\mathrm{CT}_{\text {target gene }}-\mathrm{CT}_{\text {endogenous reference }}$, and $\Delta \Delta \mathrm{Ct}=\Delta \mathrm{Ct}_{\text {sample }}-\mathrm{CT}_{\text {calibrator }}[14]$. The primer (Supplementary Table 1) was used in Real-time PCR. The amplification conditions were preincubation for hot-start DNA polymerase activity at $95^{\circ} \mathrm{C}$ for 30 seconds, followed by 45 amplification cycles at $95^{\circ} \mathrm{C}$ for 10 seconds, $61^{\circ} \mathrm{C}$ for 20 seconds, and $72^{\circ} \mathrm{C}$ for 20 seconds. The fluorescence values were collected after each elongation step to determine the threshold cycle and the cycle during the loglinear phase of the reaction at which fluorescence increased above background. At the end of the amplification cycle, a melting curve analysis was performed to determine the specificity of amplification (Supplementary Figure 1).

\section{Controlled ovarian stimulation}

Patient was stimulated using a long protocol of triptorelin and follicle stimulating hormone (FSH, MetrodinSerono, Welwyn Garden City, Herts, UK). 36 hours ovum pick up after hCG injection. Twelve oocytes were retrieved, and the luteal phase was supported by crinone $(90 \mathrm{mg} / \mathrm{d})$.

\section{Intracytoplasmic sperm injection and assisted oocyte activation}

Because all sperm were globozoospermic, those having the best motility were selected for injection. Right after ICSI, oocytes were activated with $5 \mu \mathrm{M}$ ionomycin solution for 10 minutes at $37^{\circ} \mathrm{C}$ in $6 \%$ $\mathrm{CO}_{2}, 5 \% \mathrm{O}_{2}$. After that the oocytes were thoroughly washed in fresh culture medium free of calcium ionophore and cultured in the same medium. The fertilization was evaluated after 18 hours after ICSI.

\section{Results}

Of 12 oocytes retrieved, 9 were injected with globe-headed spermatozoa. Seven oocytes remained intact and two fertilized normally. On the morning of day 3, one 8-cell embryo was transferred. A singleton clinical pregnancy resulted, caesarean delivery of a live male infant in September 2015. The infant's weight was $4.0 \mathrm{~kg}$.

\section{Discussion}

Globozoospermia, meaning round-headed spermatozoa, is a rare type of teratozoospermia first documented in 1965 [15]. In 2007, a homozygous mutation in exon 4 of SPATA16 was identified in three affected brothers from an Ashkenazi Jewish family. However, this mutation was not detected in 29 other globozoospermic patients including 6 familial cases [1]. In 2010, a homozygous missense mutation in exon 13 of PICK1 was identified in a Chinese patient with total globozoospermia and no other PICK1 mutations were identified in two additional unrelated globozoospermic patients [3]. The study of DPY19L2 knockout mice, reproducing the human globozoospermia phenotype, showed that DPY19L2 is expressed predominantly in spermatids with a very specific localization restricted to the inner nuclear membrane facing the acrosomal vesicle. In the absence of DPY19L2, the inner nuclear membrane becomes separated from the outer nuclear membrane, leading to the detachment of the acrosome associated with the outer nuclear membrane and therefore to the absence of acrosomes [16]. It has been shown that DPY19L2 is the major gene responsible for human globozoospermia $[2,17,18]$. In this case, the result indicated a homozygous deletion of the DPY19L2 gene in our patient.

Before 1994, patients with complete globozoospermia have no options for bearing a child other than using donor sperm or adoption. The first pregnancy in globozoospermia patient using ICSI method was described in 1994 [4]. Since then, numerous reports have described successful attempts to achieve either fertilization or pregnancy following ICSI with round-headed sperm $[6,19,20]$. In general, ICSI with roundheaded sperm is less successful compared with ICSI. In some cases ICSI is not always overcome the infertility associated with globozoospermia $[21,22]$. Some reports indicated that induction of oocyte activation using calcium ionophore was necessary after ICSI in some patients with globozoospermia [12,20], strongly pointing to an absence of putative oocyte-activation factor. To date, only calcium ionophore A23187 and injection of $\mathrm{CaCl}_{2}$ were used for globozoospermia patient. At least one report indicated that the fertilization rate obtained with ionomycin was higher than the activation rate using calcium ionophore A23187 on fresh oocytes after ICSI in teratozoospermic patients [23]. In the study, we used ionomycin for oocyte active after ICSI in globozoospermia patient, and a healthy male baby was delivered.

Our results indicated that ionomycin as an efficient calcium ionomycin is beneficial in patients with globozoospermia associated with DPY19L2 mutation. This study showed that the method of oocyte activation does not affect the normal growth of preimplantation embryos. Further studies are needed to confirm the safety of oocyte activation in born babies.

\section{Acknowledgments}

This work was funded by the Hebei Provincial National Natural Science Fund (H2016314002).

\section{References}

1. Dam AH, Koscinski I, Kremer JA, Moutou C, Jaeger AS, et al. (2007) Homozygous mutation in SPATA16 is associated with male infertility in human globozoospermia. Am J Hum Genet 81: 813-820. [Crossref] 
2. Koscinski I, Elinati E, Fossard C, Redin C, Muller J, et al. (2011) DPY19L2 deletion as a major cause of globozoospermia. Am J Hum Genet 88: 344-350. [crossref]

3. Liu G1, Shi QW, Lu GX (2010) A newly discovered mutation in PICK1 in a human with globozoospermia. Asian J Androl 12: 556-560. [crossref]

4. Lundin K, Sjögren A, Nilsson L, Hamberger L (1994) Fertilization and pregnancy after intracytoplasmic microinjection of acrosomeless spermatozoa. Fertil Steril 62: 12661267. [Crossref]

5. Kilani Z, Ismail R, Ghunaim S, Mohamed H, Hughes D, et al. (2004) Evaluation and treatment of familial globozoospermia in five brothers. Fertil Steril 82: 1436-1439. [crossref]

6. Dirican EK, Isik A, Vicdan K, Sozen E, Suludere Z (2008) Clinical pregnancies and livebirths achieved by intracytoplasmic injection of round headed acrosomeless spermatozoa with and without oocyte activation in familial globozoospermia: case report. Asian J Androl 10: 332-336. [Crossref]

7. Banker MR, Patel PM, Joshi BV, Shah PB, Goyal R (2009) Successful pregnancies and a live birth after intracytoplasmic sperm injection in globozoospermia. J Hum Reprod Sci 2: 81-82. [Crossref]

8. Bechoua S1, Chiron A, Delcleve-Paulhac S, Sagot P, Jimenez C (2009) Fertilisation and pregnancy outcome after ICSI in globozoospermic patients without assisted oocyte activation. Andrologia 41: 55-58. [crossref]

9. Kashir J1, Heindryckx B, Jones C, De Sutter P, Parrington J, et al. (2010) Oocyte activation, phospholipase C zeta and human infertility. Hum Reprod Update 16: 690703. [crossref]

10. Taylor SL, Yoon SY, Morshedi MS, Lacey DR, Jellerette T, et al. (2010) Complete globozoospermia associated with PLC? deficiency treated with calcium ionophore and ICSI results in pregnancy. Reprod Biomed Online 20: 559-564. [Crossref]

11. Sedo, C. A., Rawe, V. Y. and Chemes, H. E. (2012) Acrosomal biogenesis in human globozoospermia: immunocytochemical, ultrastructural and proteomic studies. Hum Reprod 27: 1912-1921. [Crossref]

12. Kuentz P, Vanden Meerschaut F, Elinati E, Nasr-Esfahani MH, Gurgan T, et al. (2013) Assisted oocyte activation overcomes fertilization failure in globozoospermic patients regardless of the DPY19L2 status. Hum Reprod 28: 1054-1061. [Crossref]

13. Lorca T, Cruzalegui FH, Fesquet D, Cavadore JC, Méry J, et al. (1993) Calmodulindependent protein kinase II mediates inactivation of MPF and CSF upon fertilization of
Xenopus eggs. Nature 366: 270-273. [Crossref]

14. Livak KJ1, Schmittgen TD (2001) Analysis of relative gene expression data using realtime quantitative PCR and the 2(-Delta Delta C(T)) Method. Methods 25: 402-408. [crossref]

15. Meyhöfer W (1965) Beitrag zur cytophotometrischen beurteilung pathologisch veränderter samenzellen unter besonderer berücksichtiging der runspermatozoen nach Feulgen-end Fast greenfärbung. Zeitschrift für Haut-und Geschlechtskrankheiten 39: 174-182.

16. Pierre V, Martinez G, Coutton C, Delaroche J, Yassine S, et al. (2012) Absence of DPY19L2, a new inner nuclear membrane protein, causes globozoospermia in mice by preventing the anchoring of the acrosome to the nucleus. Development 139: 29552965. [Crossref]

17. Harbuz R, Zouari R, Pierre V, Ben Khelifa M, Kharouf M, et al. (2011) A recurren deletion of DPY19L2 causes infertility in man by blocking sperm head elongation and acrosome formation. Am J Hum Genet 88: 351-361. [Crossref]

18. Ghédir H, Ibala-Romdhane S, Okutman O, Viot G, Saad A, et al. (2015) Identification of a new DPY19L2 mutation and a better definition of DPY19L2 deletion breakpoints leading to globozoospermia. Mol Hum Reprod 22: 35-45. [Crossref]

19. Stone S, O’Mahony F, Khalaf Y, Taylor A, Braude P (2000) A normal livebirth afte intracytoplasmic sperm injection for globozoospermia without assisted oocyte activation: case report. Hum Reprod 15: 139-141.

20. Phan V, Littman E, Harris D, La A (2015) Pregnancy after the calcium ionophore activation and aneuploid screening using A-CGH in globozoospermia patient. Human Genet Embryol 5.

21. Battaglia DE, Koehler JK, Klein NA, Tucker MJ (1997) Failure of oocyte activation after intracytoplasmic sperm injection using round-headed sperm. Fertil Steril 68: 118122. [Crossref]

22. Rybouchkin AV, Van der Straeten F, Quatacker J, De Sutter P, Dhont M (1997) Fertilization and pregnancy after assisted oocyte activation and intracytoplasmic sperm injection in a case of round-headed sperm associated with deficient oocyte activation capacity. Fertil Steril 68: 1144-1147. [Crossref]

23. Nasr-Esfahani MH, Razavi S, Javdan Z, Tavalaee M (2008) Artificial oocyte activation in severe teratozoospermia undergoing intracytoplasmic sperm injection. Fertil Steril 90: 2231-2237. [Crossref]

Copyright: (C2016 Liu S. This is an open-access article distributed under the terms of the Creative Commons Attribution License, which permits unrestricted use, distribution, and reproduction in any medium, provided the original author and source are credited. 